\title{
Analysis of Heavy Metals in Sediments from Northern Moroccan Coast Using Simple and Low-Cost Methodology
}

\author{
Mostapha Benomar ${ }^{*}, 1,2$, Carolina Mendiguchía ${ }^{2}$, Hassan Er-Raioui ${ }^{3}$, Mohammed Marhraoui ${ }^{4}$, \\ Ghizlane Lafraoui ${ }^{1}$, Mohammed Karim Oulad-Abdellah ${ }^{4}$, Manuel García-Vargas ${ }^{2}$ and \\ Carlos Moreno ${ }^{2}$
}

\author{
${ }^{I}$ National Institute of Halieutic Research, BP 5268 Dradeb, Tangier, Morocco \\ ${ }^{2}$ Department of Analytical Chemistry, Faculty of Marine and Environmental Sciences, University of Cádiz, 11510 \\ Puerto Real (Cádiz), Spain \\ ${ }^{3}$ Group of Geosciences and Environment, Faculty of Sciences and Techniques, University Abdelmalek Esaadi, BP 416, \\ Tangier, Morocco \\ ${ }^{4}$ National Institute of Halieutic Research, BP 31, M'diq, Morocco
}

\begin{abstract}
A new simple and low-cost digestion method for sediment samples was studied and optimized. It was based on the acid digestions of samples into low-pressure PTFE bombs and heating in a simple convection-based oven, as an alternative to available standard methods based on high-pressure bombs and microwave ovens. Although there is no doubt about the benefits of microwave-based methodologies, there is still a problem related with the high cost of the equipment required, making difficult its practical application in some developing countries. The proposed methodology was optimized by using three certified reference materials (CRMs): marine sediment (GBW07313), estuarine sediment (SRM1646a) and river sediment (CRM320), which were digested separately by the two studied methods. Metal concentrations in the digested extracts were analyzed and compared. Average metals recoveries obtained with the new method ranged from $61 \%(\mathrm{Al})$ to $100 \%(\mathrm{Cd}, \mathrm{Co}, \mathrm{Pb})$, and, in general, significant differences between the two methodologies were not observed.

The new digestion method was applied to the simultaneous determination of up to ten heavy metals in marine sediments from the Northern Moroccan coastline, in the Mediterranean province of Tetouan and Chefchaouen. The results obtained ranged from 1.26-3.32\% for Al, 16.2-20.7 mg/kg for Co, 49.7-72.7 mg/kg for Cr, 20.2-32.3 mg/kg for Cu, 2.98-3.92\% for Fe, 184-394 for Mn, 34.5-44.3 mg/kg for Ni, 36.0-49.7 mg/kg for Pb, 0.46-0.55 \% for Ti, and 67.5-83.6 mg/kg for Zn.

A statistical data analysis was performed in order to determine the sources of heavy metals in this area. Relatively high concentrations of $\mathrm{Cr}$, $\mathrm{Ni}$ and $\mathrm{Pb}$ were measured in all the sampling sites, although their anthropogenic origin could not be established. In addition, $\mathrm{Cu}$ and organic matter were enriched in sediments close to agricultural areas.
\end{abstract}

Keywords: Sediments, heavy metals, anthropogenic pollution, acid digestion, Moroccan coast.

\section{INTRODUCTION}

Morocco, with more than $3500 \mathrm{~km}$ of coastline, finds in the marine environment one of the main basis of its economy, with fishing and tourism being the most prominent activities undertaken. For this reason, an effort is being made to establish and preserve the environmental quality of littoral zones, including the levels of different pollutants in Moroccan coast. These studies allowed the identification of contamination sources and the establishment of control measures if necessary [1-3].

In this context, the knowledge of heavy metals distribution in aquatic environments is of main interest due to their potential harmful effects on aquatic organisms, even at very low concentration, and they can be related with differ-

*Address correspondence to this author at the National Institute of Halieutic Research, BP 5268 Dradeb, Tangier, Morocco; Tel: +212-539946586/87; Fax:+212-539325139; E-mail: mostapha.benomar@uca.es ent anthropogenic activities. Besides, aquatic sediments can play an important role as a trap of metallic elements. These metals may present both natural and anthropogenic origin [4], and then, they can be used as tracers of different anthropogenic activities [5, 6]. In this sense, high concentrations of $\mathrm{Zn}, \mathrm{Cu}$ and $\mathrm{Pb}$ in marine sediments have been related to industry, urban settlements or aquaculture activities [7, 8].

Although several methodologies may be used to analyze metals in aquatic sediments, most of them are based on a previous sample digestion before metal quantification by different analytical techniques. The objective of the digestion step is to achieve a selective or complete extraction of metals from the sediment, while sample contamination is prevented. Mostly, the digestion procedures are based on the addition of inorganic acids in a closed vessel, which may be heated with different sources. For instance, aqua regia, $\mathrm{HNO}_{3}-\mathrm{HF}, \mathrm{HF}$ $\mathrm{HNO}_{3}-\mathrm{H}_{2} \mathrm{SO}_{4}-\mathrm{HClO}_{4}, \mathrm{HNO}_{3}-\mathrm{HClO}_{4}$ has been proved to extract metals from sediments with variable effectiveness, and the addition of $\mathrm{HF}$ is always required to dissolve the 
silica matrix if a complete digestion is needed [9-12]. In addition to the acid mixture used, the selection of the heating source has been also reported to have strong influence in the digestion efficiency. In this sense, the use of microwaveassisted digestion is much extended, since it presents several advantages such as the use of small acid volumes, the reduction of the extraction time and the prevention of a possible loss of volatile elements caused by warming up the sample $[10,13]$. Nevertheless, the main drawback of microwave systems is the high cost of the equipment required (both the oven and the bombs) that may be up to 50-100 times higher than convection ovens. This fact is very important especially in developing countries where the microwave systems are usually not available. For this reason, the development and optimization of less expensive digestion methodologies are also required.

In this work, a digestion method based on low-pressure PTFE bombs and a simple and low-cost convection-oven has been optimized and applied to the analysis of metals in marine sediments of the Morocco's Mediterranean coast.

\section{MATERIALS AND METHODS}

\subsection{Study Area and Sampling}

Two sampling areas were selected in the Morocco's Mediterranean Coast, in the Province of Tetouan and Chefchaouen (Fig. 1). The first one was close to the urban area of Martil, and it receives the urban discharges from Martil city and Tetouan district. This zone is characterized by an important industrial and tourist activity, particularly in summer. The second sampling area, namely Oued Laou, is relatively far away from any urban area, although in this area is located the mouth of the Oued Laou River, which receives agricultural and untreated urban discharges.

The sediments analyzed were taken in October 2007. Sampling was carried out in four different sites in each sampling area following a transect perpendicular to the shoreline. A detailed description of each sampling point is presented in Table 1. In each sampling site superficial sediments $(5 \mathrm{~cm}$ depth) were taken in duplicate by using a Van Veen grab $(305 \mathrm{~mm} \times 305 \mathrm{~mm})$, and avoiding sediment

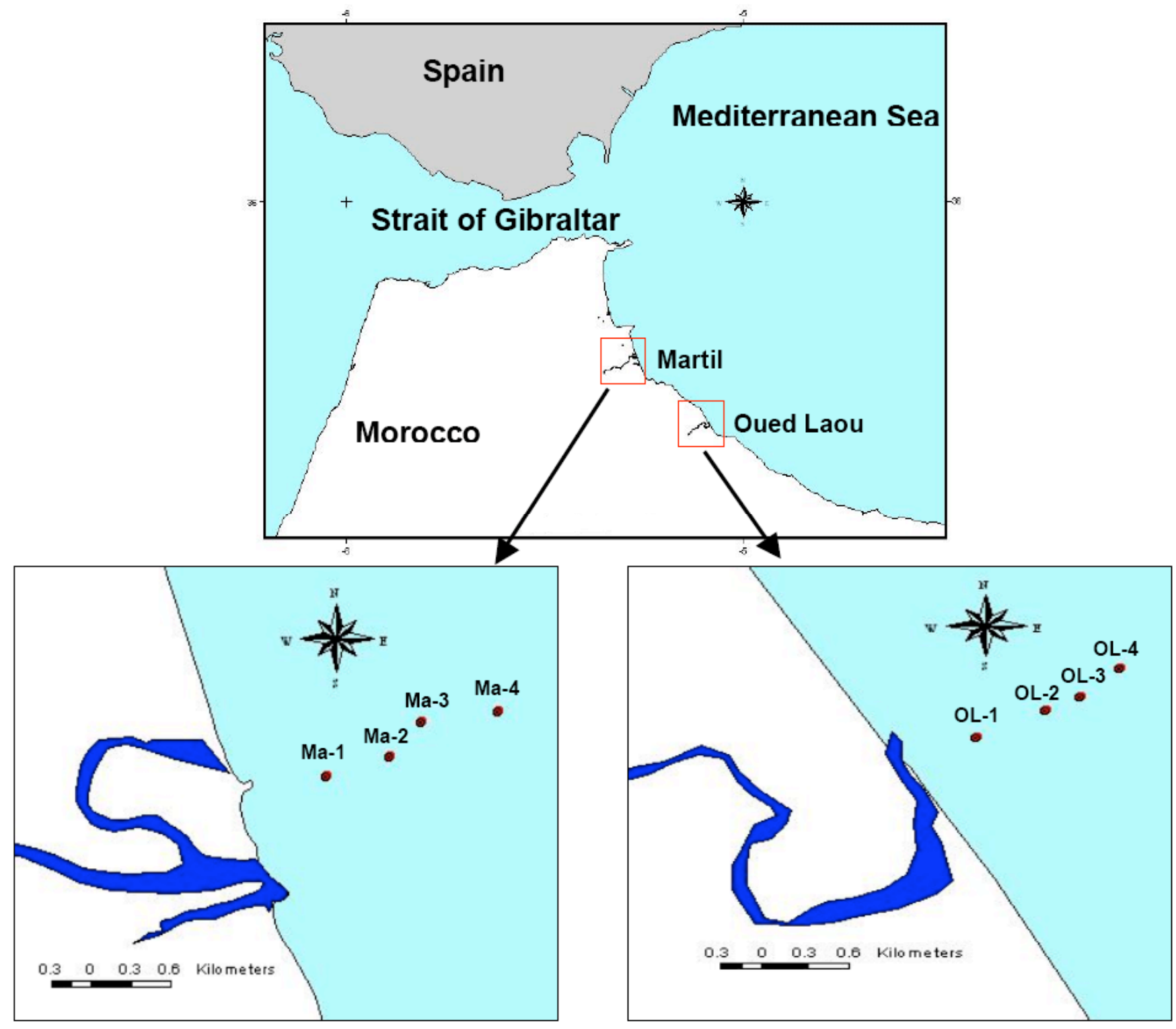

Fig. (1). Sampling stations of sediment in the Northern Moroccan coast. 
Table 1. Description of the Sampling Stations in Mediterranean Moroccan Coast

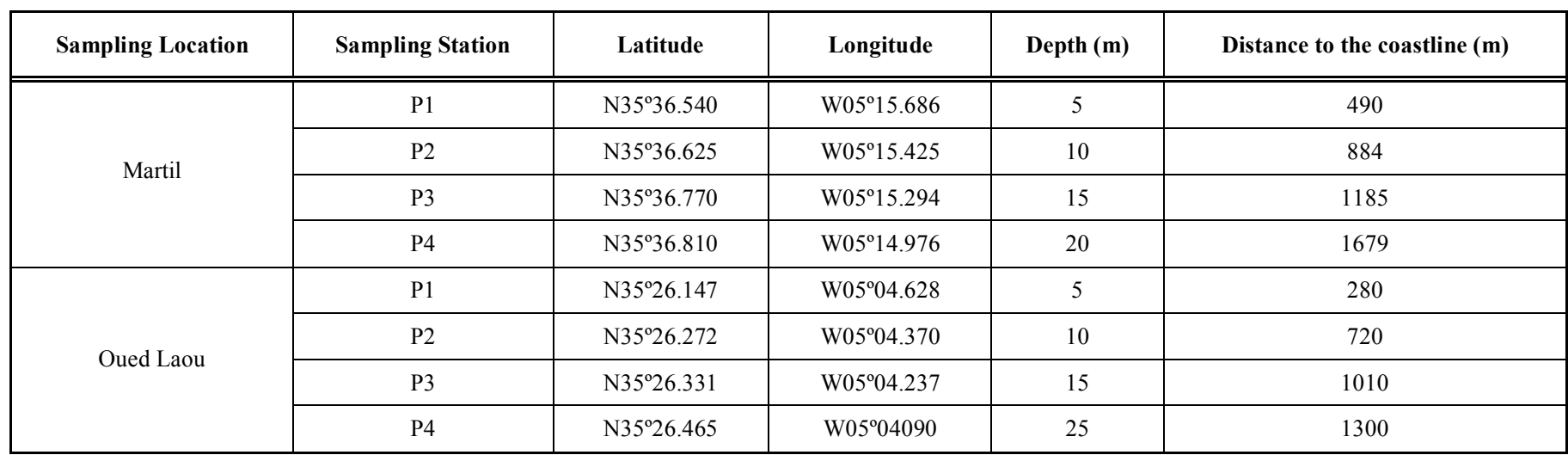

loss as far as possible. Analytical procedures were performed with $<63 \mu \mathrm{m}$ fraction, previously separated by wet sieving, dried at $105^{\circ} \mathrm{C}$ until constant weight, and crushed before acid digestion.

\subsection{Reagents and Solutions}

All the acids used were of analytical reagent grade. Nitric acid $(65 \% \mathrm{w} / \mathrm{v})$, hydrofluoric acid $(40 \% \mathrm{w} / \mathrm{v})$, sulphuric acid $(98 \% \mathrm{w} / \mathrm{v})$, and hydrochloric acid $(35 \% \mathrm{w} / \mathrm{v})$ were obtained from Scharlab (Spain). Potassium dichromate, ammonium iron (II) sulphate hexahydrate and ferroin (0.025 M solution) were also purchased from Scharlab (Spain). Aqueous standards solutions of metals (Al, Co, Cr, Cu, Fe, Mn, Ni, $\mathrm{Pb}, \mathrm{Ti}$, and $\mathrm{Zn}$ ) were prepared from $1,000 \mathrm{mg} \mathrm{L}^{-1}$ standard solutions obtained from Merck (Germany). All solutions were prepared with deionized water $\left(18 \mathrm{M} \Omega \cdot \mathrm{cm}^{-1}\right)$ from a Milli-Q analytical reagent grade water purification system (Millipore, Bedford, MA).

Three CRMs, were used to optimize the digestion method. The first one was marine sediment (GBW 07313), purchased from the National Research Center for Certified Reference Materials (China). The second was estuarine sediment (SRM1646a) prepared by the National Institute of Standards and Technology (USA) and the third one was river sediment (CRM320) supplied by the European Community Bureau of Reference (Belgium).

\subsection{Apparatus}

A microwave oven Ethos (Milestone, Italy) with temperature control and a convection oven P-Selecta (Selecta, Spain) were used to perform the digestion of the sediment samples. After the digestion step, the extracted metals were analyzed by an inductively coupled plasma atomic emission spectrometer (ICP-AES) IRIS Intrepid (Thermo Elemental, United Kingdom).

When the convection oven was used, samples digestions were carried out by using PTFE chemically inert bottles (Brand, USA). Before each digestion, they were soaked overnight into a mixture of $\mathrm{HNO}_{3}$ and $\mathrm{HCl}(5: 2)$.

\subsection{Digestion Procedures}

The metals analyzed in the sediments were $\mathrm{Al}, \mathrm{Co}, \mathrm{Cr}$, $\mathrm{Cu}, \mathrm{Fe}, \mathrm{Mn}, \mathrm{Ni}, \mathrm{Pb}, \mathrm{Ti}$, and $\mathrm{Zn}$. To optimize the analytical method, the three CRMs mentioned before were digested by using both microwave and convection heating procedures. EPA method 3052 was adapted to reduce the amount of sample and consequently the volume of acids [14]. Thus, 0.2 $\mathrm{g}$ of dry sediment $(<63 \mu \mathrm{m})$ was placed in each microwave PTFE vessel and $1 \mathrm{~mL} \mathrm{HF}$ plus $4 \mathrm{~mL} \mathrm{HNO}_{3}$ were added. The microwave heating program consisted of two steps. First, the temperature was slowly increased up to $180{ }^{\circ} \mathrm{C}$ during $5 \mathrm{~min}$ and then, microwave radiation was used to maintain a constant temperature of $180{ }^{\circ} \mathrm{C}$ for $15 \mathrm{~min}$. Once PTFE bombs cooled down, the extracts were filtered, if required, and transferred into $50-\mathrm{mL}$ volumetric flasks. Finally, the solutions were kept in acid-cleaned polyethylene bottles at 4 ${ }^{\circ} \mathrm{C}$ until their analysis.

The convection-based procedure was identical, but substituting the microwave oven by a convection oven, and heating the samples at $105{ }^{\circ} \mathrm{C}$ for 24 hours. The results obtained with both methods were statistically compared to confirm the applicability of the convection-based methodology to the analysis of real samples collected in the Moroccan coast.

\subsection{Analysis of Organic Matter}

To analyze the concentration of organic matter in the samples, $0.2 \mathrm{~g}$ of sediment were taken and oxidized for 30 min with $10 \mathrm{~mL}$ of $\mathrm{K}_{2} \mathrm{Cr}_{2} \mathrm{O}_{7} 0.083 \mathrm{M}$ plus $10 \mathrm{~mL}$ of $\mathrm{H}_{2} \mathrm{SO}_{4}$. Then, the excess $\mathrm{K}_{2} \mathrm{Cr}_{2} \mathrm{O}_{7}$ was measured by back-titration with $\mathrm{Fe}\left(\mathrm{NH}_{4}\right)_{2}\left(\mathrm{SO}_{4}\right)_{2} \cdot 6 \mathrm{H}_{2} \mathrm{O}$ and ferroine as indicator. A blank titration was carried out for each determination [15].

\subsection{Statistical Procedures}

The concentrations obtained in the analyses of the CRMs by both digestion methodologies were compared by using the Student's t-test [16] and, on the other hand, metal recoveries were compared using ANOVA or Kruskal-Wallis tests. Finally, for data interpretation, the concentrations of 
Table 2. Total Metal Concentrations in Three Certified Sediments Obtained by Using Digestion Procedures Based on Microwave and Convection Ovens

\begin{tabular}{|c|c|c|c|c|c|c|c|c|c|c|c|}
\hline \multicolumn{2}{|c|}{ Sample } & Al (\%) & Co $(\mathrm{mg} / \mathrm{kg})$ & $\mathrm{Cr}(\mathrm{mg} / \mathrm{kg})$ & $\mathrm{Cu}(\mathrm{mg} / \mathrm{kg})$ & Fe $(\%)$ & Mn (mg/kg) & Ni (mg/kg) & $\mathrm{Pb}(\mathrm{mg} / \mathrm{kg})$ & Ti (\%) & $\mathrm{Zn}(\mathrm{mg} / \mathrm{kg})$ \\
\hline \multirow{3}{*}{ GBW 07313} & Certified & - & $76.6 \pm 3.2$ & $58.4 \pm 3$ & $424 \pm 19$ & - & - & $150 \pm 8$ & $29.3 \pm 2.4$ & - & $160 \pm 6$ \\
\hline & Microwave & $6.4 \pm 0.2$ & $78.2 \pm 4.4$ & $43.7 \pm 3.0$ & $401.2 \pm 27.5$ & $4.0 \pm 0.1$ & $3171.4 \pm 212.7$ & $159.2 \pm 14.4$ & $24.0 \pm 2.8$ & $0.4 \pm 0.1$ & $107.7 \pm 5.1$ \\
\hline & Convection & $5.6 \pm 0.1$ & $62.2 \pm 10.5$ & $44.9 \pm 6.6$ & $398.7 \pm 10.0$ & $4.0 \pm 0.1$ & $2273 \pm 548.1$ & $133.1 \pm 6.6$ & $32.9 \pm 6.5$ & $0.3 \pm 0.1$ & $143.9 \pm 6.9$ \\
\hline \multirow{3}{*}{ SRM1646a } & Certified & $2.3 \pm 0.1$ & $5^{*}$ & $40.9 \pm 0.9$ & $10.0 \pm 0.1$ & $2.0 \pm 0.1$ & $234.5 \pm 1.4$ & $23^{*}$ & $11.7 \pm 0.6$ & $0.5 \pm 0.1$ & $48.9 \pm 0.8$ \\
\hline & Microwave & $1.8 \pm 0.5$ & $5.0 \pm 0.8$ & $27.3 \pm 1.5$ & $7.0 \pm 0.6$ & $1.9 \pm 0.1$ & $242.7 \pm 15.9$ & $21.8 \pm 0.8$ & $14.6 \pm 3.3$ & $0.4 \pm 0.1$ & $33.0 \pm 0.5$ \\
\hline & Convection & $1.5 \pm 0.6$ & $6.5 \pm 1.7$ & $25.7 \pm 3.3$ & $7.9 \pm 1.6$ & $1.8 \pm 0.1$ & $175.1 \pm 22.0$ & $16.7 \pm 0.7$ & $10.6 \pm 3.2$ & $0.4 \pm 0.1$ & $38.0 \pm 1.8$ \\
\hline \multirow{3}{*}{ CRM320 } & Certified & $7.9 \pm 0.5^{*}$ & $19.4 \pm 1.5$ & $138.0 \pm 3.5$ & $44.1 \pm 0.5$ & $4.5 \pm 0.2$ & $740.2 \pm 62.5^{*}$ & $75.2 \pm 2.8$ & $42.3 \pm 1.6$ & $0.5 \pm 0.1^{*}$ & $142.0 \pm 6$ \\
\hline & Microwave & $5.1 \pm 0.9$ & $23.2 \pm 1.2$ & $89.6 \pm 5.2$ & $44.2 \pm 12.4$ & $3.8 \pm 0.1$ & $760.8 \pm 52.2$ & $78.6 \pm 5.6$ & $43.4 \pm 2.8$ & $0.5 \pm 0.1$ & $93.8 \pm 5.2$ \\
\hline & Convection & $3.0 \pm 1.4$ & $19.9 \pm 1.9$ & $82.7 \pm 8.1$ & $35.7 \pm 8.9$ & $3.5 \pm 0.2$ & $435.9 \pm 67.6$ & $66.5 \pm 5.6$ & $43.1 \pm 5.0$ & $0.5 \pm 0.1$ & $107.1 \pm 7.1$ \\
\hline
\end{tabular}

heavy metals in the sediments from north Moroccan coast were analyzed by principal components analysis (PCA). All statistics were performed using the SPSS15 software (http://www.spss.com).

\section{RESULTS AND DISCUSSION}

\subsection{Digestion Procedures}

The results obtained for the analysis of three CRMs by the new method (convection-based) and the reference method (microwave-based) are reported in Table 2. As observed, some elements such as $\mathrm{Al}, \mathrm{Cr}, \mathrm{Cu}$ or $\mathrm{Mn}$ presented non-quantitative recoveries by both methods. For this reason, the use of a higher volume of hydrofluoric acid $(2 \mathrm{~mL})$ was tested in order to improve the recoveries without success. Similar results were reported by several authors for $\mathrm{Al}, \mathrm{Cr}$ or $\mathrm{Cu}[17,18]$.

As suggested by the results of the Student's t-test presented in Table 3, the results obtained by both methods were, in general, very similar. Null hypothesis was always accepted except for $\mathrm{Al}$ and $\mathrm{Zn}$ in the marine sediment. This fact could be related with the observed partial solution of few refractory sample matrix compounds, such as alumina, and other oxides [14].

Average recoveries were calculated for each metal. With this aim, we took into consideration up to three recovery values, corresponding to the three CRMs analyzed by using the proposed convection method. To compare these values, Student's t-test was used if only two values were available, while ANOVA or Kruskal-Wallis test were used to compare the three values at a time. Final recovery values were estimated from marine sediment plus, if no significant different observed, estuarine and/or river sediment. The values obtained, and used to calculate metal concentrations in Moroccan sediments, were: $\mathrm{Al}(61 \%), \mathrm{Fe}(93 \%)$, Ti (92 $\%)$, Mn (75\%), Co (100\%), Cr (76\%), Cu (86\%), Ni (95 $\%), \mathrm{Pb}(100 \%)$, and $\mathrm{Zn}(90 \%)$.

\subsection{Distribution of Heavy Metals and Organic Matter in Marine Sediments of the Moroccan Coast}

The results obtained for the two sampling locations studied (Martil and Oued Laou) are presented in Figs. (2-4), for major and minor heavy metals, and organic matter,

Table 3. Comparison between the Concentrations Obtained by the Two Heating Methodologies Using Student's t-Test

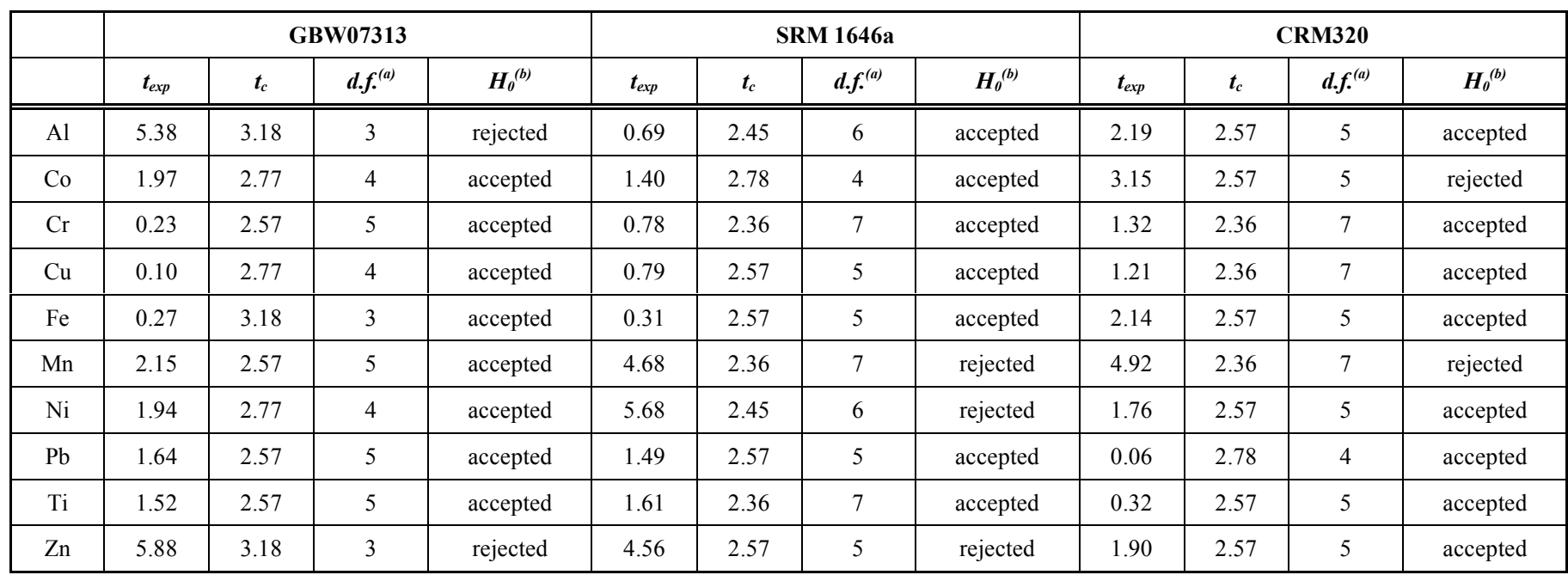

(a) d.f.: degrees of freedom [15]; (b) $\mathrm{H}_{0}$ : Both heating methods give the same result. 

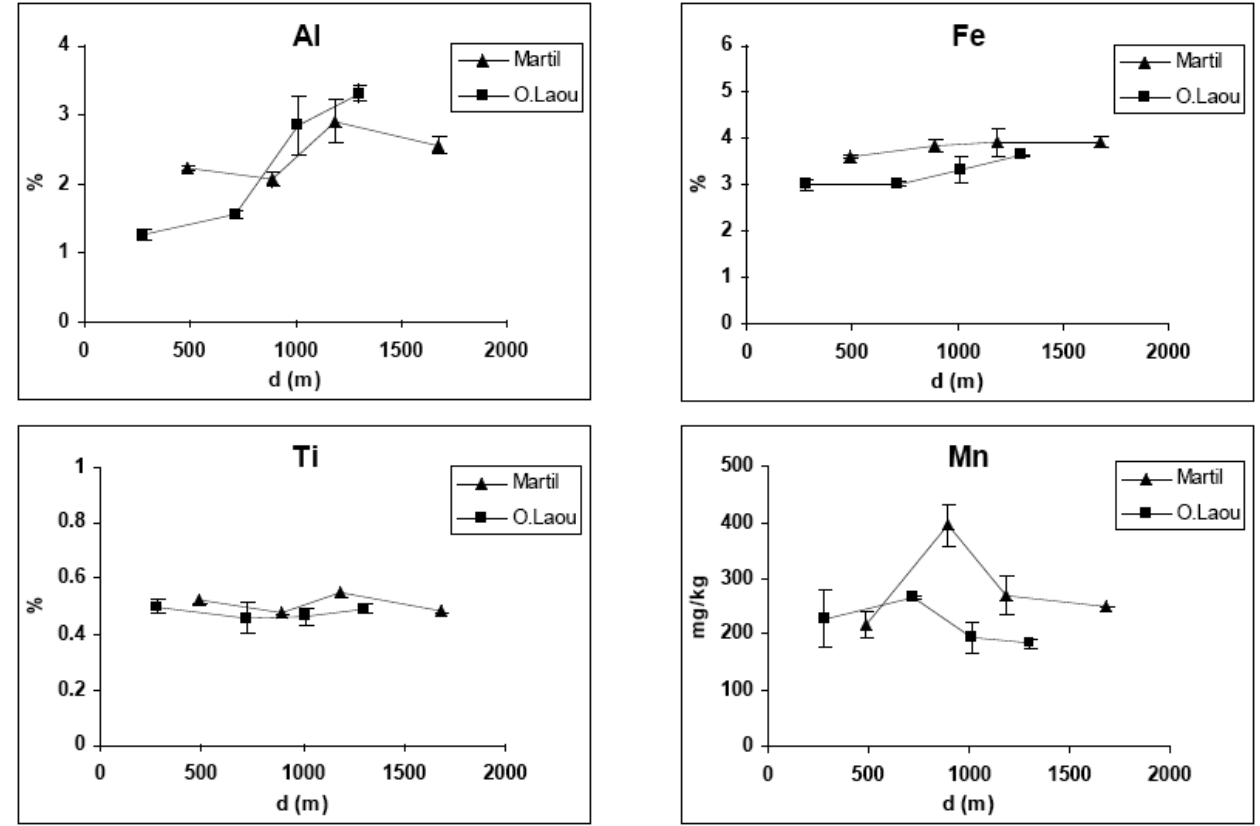

Fig. (2). Concentrations (\% dry sediment) of $\mathrm{Al}, \mathrm{Fe}, \mathrm{Ti}$ and $(\mathrm{mg} / \mathrm{kg}$ dry sediment) of $\mathrm{Mn}$ in coastal sediments from Martil ( $\boldsymbol{\Delta})$ and Oued Laou (ロ).
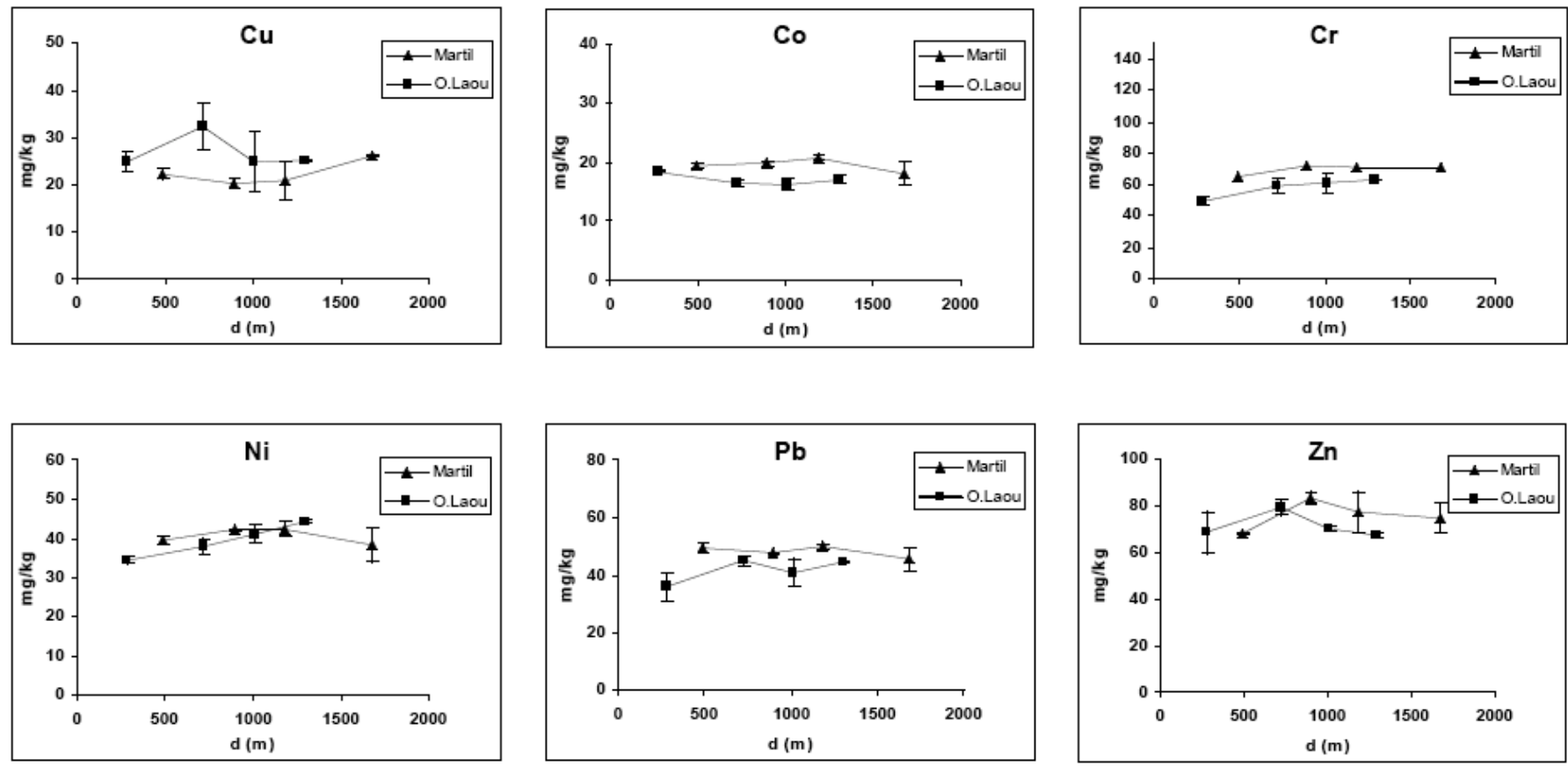

Fig. (3). Concentrations of $\mathrm{Cu}, \mathrm{Co}, \mathrm{Cr}, \mathrm{Ni}, \mathrm{Pb}$, and $\mathrm{Zn}$ in $\mathrm{mg} / \mathrm{kg}$ dry sediment in coastal sediments from Martil ( $\mathbf{\Delta})$ and Oued Laou ( $\mathbf{\square})$.

respectively. In both sampling areas the concentrations of metals in the sediments were almost invariable with distance to the coast. This fact could be related with the presence of rivers mouths in both zones which could contribute to the homogenization of the sediments even at large distances from the coast. Nevertheless slight deviations from this general trend were observed for some elements. Thus, while Al increased its concentration with distance from the coast, Mn exhibited their highest concentrations in Martil in the second sampling station, about 700-900 meters away from the coastline. Since no pollution effect could be established in this location, this higher concentration could be likely due to natural reasons, although this fact could not be established.

The concentrations of metals measured in Martil were in general higher than those measured in Oued Laou. The only exception was obtained for copper, suggesting a specific input of this element in the zone of Oued Laou. This input could be also responsible of the higher contents of organic matter measured in this zone, and it could be probably related with agriculture which is the main anthropogenic 


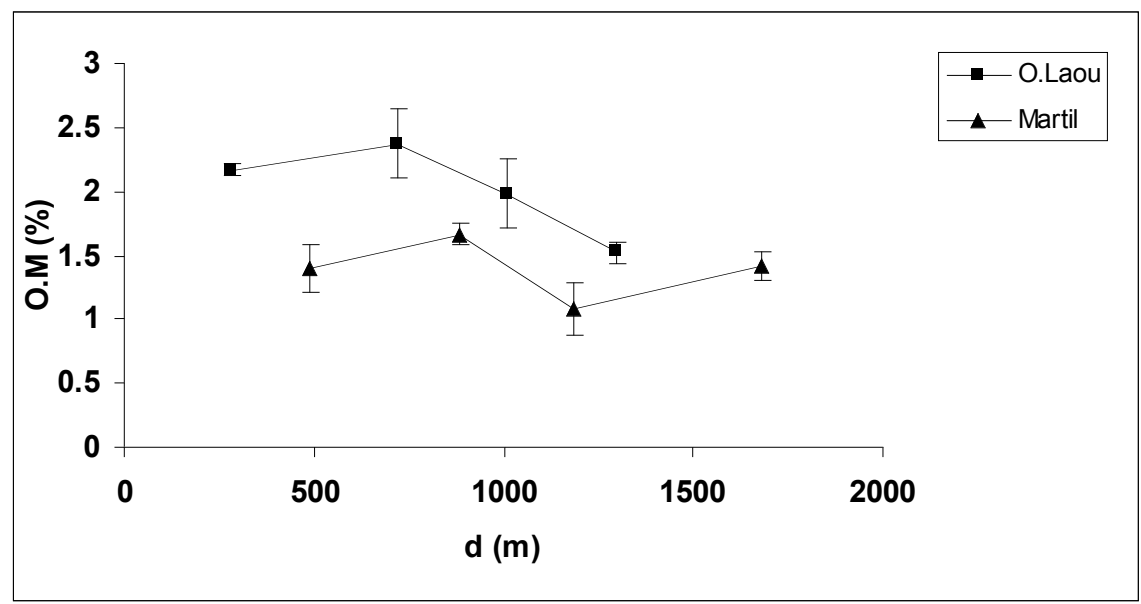

Fig. (4). Concentrations (\%) of organic matter in coastal sediments from Martil ( $\mathbf{\Delta})$ and Oued Laou (घ).

activity in the area. High copper concentrations in sediments have been previously related to agricultural activities in other zones [19].

If compared with the values reported by the most frequently used Sediment Quality Guidelines (SQGs), such as those developed by the Canadian environmental authority (Environment Canada) [20] and the American National Oceanic and Atmospheric Administration (NOAA) [21], the concentrations of $\mathrm{Cr}, \mathrm{Pb}$ and $\mathrm{Ni}$ were above the recommended quality values, although they did not exceed the values causing probable effects in the organisms. On the other hand, if compared with a more local SQG developed for the Gulf of Cádiz (close to the Strait of Gibraltar), our results indicate a moderate pollution by $\mathrm{Cu}, \mathrm{Ni}$, and $\mathrm{Pb}$, and a high pollution by Co [22].

\subsection{Statistical Analysis}

Multivariate analysis by principal components analysis (PCA) with standardized data was used for a better interpretation of the results obtained in the sediments of the Moroccan coast. Three principal components with eigenvalues higher than 1 were extracted, explaining $88.7 \%$ of the variance of the system. As reported in Table 4, the first one

Table 4. Factor Loadings for Metal Concentrations in the Sediments

\begin{tabular}{|c|c|c|c|}
\hline & PC1 & PC2 & PC3 \\
\hline $\mathbf{A l}$ & 0.517 & $\mathbf{- 0 . 7 6 1}$ & 0.351 \\
\hline $\mathbf{C o}$ & $\mathbf{0 . 7 4 7}$ & 0.262 & -0.609 \\
\hline $\mathbf{C r}$ & $\mathbf{0 . 9 1 9}$ & 0.065 & 0.300 \\
\hline $\mathbf{C u}$ & $\mathbf{- 0 . 7 3 1}$ & 0.117 & 0.446 \\
\hline $\mathbf{F e}$ & $\mathbf{0 . 9 2 7}$ & -0.140 & 0.089 \\
\hline $\mathbf{M n}$ & 0.499 & $\mathbf{0 . 8 2 8}$ & 0.100 \\
\hline $\mathbf{N i}$ & 0.659 & -0.453 & 0.450 \\
\hline $\mathbf{P b}$ & $\mathbf{0 . 8 3 7}$ & 0.043 & 0.139 \\
\hline $\mathbf{T i}$ & 0.514 & -0.278 & $\mathbf{- 0 . 7 3 6}$ \\
\hline $\mathbf{Z n}$ & 0.440 & $\mathbf{0 . 7 8 5}$ & 0.355 \\
\hline
\end{tabular}

explained most of the variation of most minor elements, such as $\mathrm{Co}, \mathrm{Cr}, \mathrm{Cu}$, and $\mathrm{Pb}$, as well as $\mathrm{Fe}$, indicating a similar source for these elements probably related to anthropogenic activities. Besides, only copper presented a negative load indicating a probably different anthropogenic source for this element in comparison with the others. The $2^{\text {nd }}$ and $3^{\text {rd }}$ PCs explained the major source of variation for most major elements, such as $\mathrm{Al}, \mathrm{Zn}$, and $\mathrm{Mn}$, in the second, and $\mathrm{Ti}$ in the third one, being related to natural sources. $\mathrm{Ni}$ was distributed between the three components indicating a mixed (natural and anthropogenic) origin in the studied area.

To establish the sources of metals in the area, scores of sampling sites and loadings of variables are represented in Fig. (5), for the first two PCs. As can be observed, sampling stations corresponding to Martil and Oued Laou are clearly separated by the signal of the first PC. Besides, as mentioned before, $\mathrm{Cu}$ is the unique variable that presents higher concentrations in Oued Laou, and it is now separated from the rest of the variables, confirming its different origin, probably associated to agriculture as it was explained before.

The other metals appeared all together, and close to Martil sampling stations, suggesting a high homogeneity in the composition of the sediments of the area. Nevertheless three different metals subgroups could be separated. The first group included some elements that appeared at high concentrations in the samples, such as $\mathrm{Co}, \mathrm{Pb}, \mathrm{Cr}$ and $\mathrm{Fe}$, and they could be related to the anthropogenic activities developed in Martil area, mainly urban and industrial activities. Similar association between $\mathrm{Fe}$ and $\mathrm{Cr}$ has been observed in sediments from rivers located in the Tangier area related to industrial activities, although in that case $\mathrm{Ni}$ and $\mathrm{Cu}$ were also related to industrial and urban sources [23]. The second group included the lithogenic elements $\mathrm{Ti}$ and $\mathrm{Al}$, as well as $\mathrm{Ni}$, suggesting that the high concentrations of this metal measured in the samples could not be clearly related to anthropogenic pollution. In this sense, high natural concentrations of $\mathrm{Ni}$ in crust have been previously described [24]. The third subgroup included $\mathrm{Mn}$ and $\mathrm{Zn}$ and, in this case, its origin appears related to natural sources, although the presence of anthropogenic $\mathrm{Zn}$ has been reported in other studies dealing with the Moroccan coastal sediments $[25,26]$. 


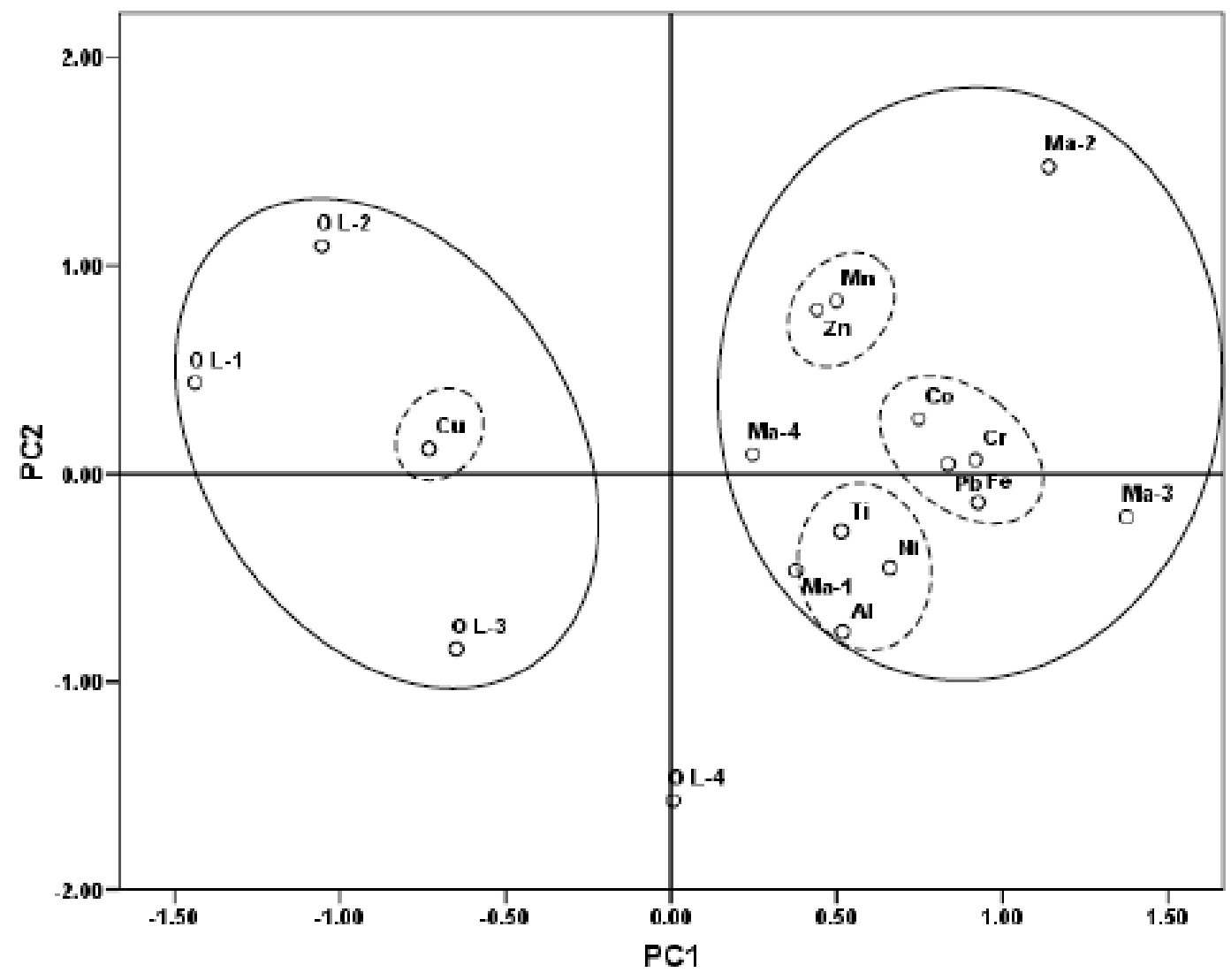

Fig. (5). Principal component analysis (PCA) for $\mathrm{Al}, \mathrm{Fe}, \mathrm{Ti}, \mathrm{Mn}, \mathrm{Cu}, \mathrm{Co}, \mathrm{Cr}, \mathrm{Ni}, \mathrm{Pb}$ and $\mathrm{Zn}$ in sediment collected from the Northern Morocco coast.

\section{CONCLUSIONS}

The results obtained for the determination of heavy metals in aquatic sediments by means of an acidic digestion of the samples in low pressure PTFE bombs and convection heating were significatively equal to those obtained by the more sophisticated and expensive methodology based on microwave ovens. The new methodology was applied to the analysis of metals in sediments from two different areas of the Mediterranean coast of Morocco. The results obtained suggested that, in general, metal concentrations were very similar in both studied areas, and presented low variability with distance to the coast, indicating high homogeneity in the sediments, probably caused by the presence of river mouths. Data analysis by PCA classified metals in three different groups: on the one hand, $\mathrm{Co}, \mathrm{Cr}, \mathrm{Pb}$, and $\mathrm{Fe}$, which appeared at high concentrations probably due to anthropogenic activities; on the other hand, $\mathrm{Al}, \mathrm{Ti}, \mathrm{Mn}, \mathrm{Zn}$, and $\mathrm{Ni}$, which are likely to have a natural origin (probably mixed with anthropic in the case of $\mathrm{Ni}$ ); finally, $\mathrm{Cu}$ presented a different and particular behavior, and was the only metal with lower concentrations in Martil than in Oued Laou, an area where agriculture activities are quite developed. Regardless of their origin, the results obtained reported high concentrations of several metals, such as $\mathrm{Co}, \mathrm{Cr}, \mathrm{Ni}$, and $\mathrm{Pb}$, even higher than those values included in SQGs. More studies are necessary in the area to clarify the sources of these metals and to establish if control measurements would be required in the area.

\section{CONFLICT OF INTEREST}

None declared.

\section{ACKNOWLEDGEMENTS}

This work has been financed by the Agencia Española de Cooperación Internacional (Ref. A/5448/06 - A/7690/07). The collaboration of the Servicio Central de Ciencia y Tecnología (División de Espectroscopía) of the University of Cádiz is acknowledged.

\section{REFERENCES}

[1] González I, Águila E, Galán E. Partitioning, bioavailability and origin of heavy metals from the Nador lagoon sediments (Morocco) as a basis for their management. Environ Geol 2007; 52: 1581-93.

[2] Blinda M, Sabhi Y, El Quesear S, Fekhaoui M, Aït Brahim L. Dynamics of heavy-metal transfer between biotic (Cytheria chione and Cerastoderma edule) and abiotic (water and sediment) components in marine environment (Bay of Martil, Moroccan Mediterranean coast). Chem Ecol 2005; 21: 279-301.

[3] Banaoui A, Chiffoleau JF, Moukrim A, et al. Trace metal distribution in the mussel Perna perna along the Moroccan coast Mar Pol Bull 2004; 48: 378-402.

[4] Sources and Origins of Heavy Metals, In: Bradl HB, Ed. Heavy Metals in the Environment: Origin, Interaction and Remediation. Amsterdam: Elsevier, 2005.

[5] Mendiguchía C, Moreno C, García-Vargas M. Evaluation of natural and anthropogenic influences on the Guadalquivir River (Spain) by dissolved heavy metals and nutrients. Chemosphere 2007; 69: 1509-17. 
[6] Mendiguchía C, Moreno C, Galindo-Riaño MD, García-Vargas M. Using chemometric tools to assess anthropogenic effects in river waters: A case study; the Guadalquivir River (Spain). Anal Chim Acta 2004; 515: 143-9.

[7] Tejeda S, Zarazúa-Ortega G, Avila-Pérez P, García-Mejía A, Carapia-Morales L, Diaz-Delgado C. Major and trace elements in sediments of the upper course of Lerma river. J Radioanal Nucl Chem 2006; 270: 9-14.

[8] Mendiguchía C, Moreno C, Mánuel-Vez MP, García-Vargas M. Preliminary investigation on the enrichment of heavy metals in marine sediments originated from intensive aquaculture effluents. Aquaculture 2006; 254: 317-25.

[9] Jeneper ML, Hayao S. Comparison of the acid combinations in microwave-assisted digestion of marine sediments for heavy metal analyses. Anal Sci 2005; 21: 1181-4.

[10] Nieuwenhuize J, Poley-Vos CH, Van den Akker AH, Van Delft W. Comparison of microwave and conventional extraction techniques for the determination of metals in soil, sediment, and sludge samples by atomic spectrometry. Analyst 1991; 116: 347-51.

[11] Scancar J, Milacic R, Horvat M. Comparison of various digestion and extraction procedures in analysis of heavy metals in sediments. Wat Air Soil Poll 2000; 118: 87-99.

[12] Hseu ZY, Chen ZS, Tsai CC, et al. Digestion methods for total heavy metals in sediments and soils. Wat Air Soil Poll 2002; 141: 189-205.

[13] Mitra S, Eds. Sample preparation techniques in analytical chemistry. New Jersey: Hoboken John Wiley \& Sons Inc WileyInterscience 2003

[14] USEPA 3052, Microwave assisted acid digestion of siliceous and organically based matrices. December 1996.

[15] Radojevic M, Bashkin VN. Practical environmental analysis. Cambridge: The Royal Society of Chemistry 1999.

[16] Miller JN. Statistics and Chemometrics for Analytical Chemistry. Harlow: Prentice Hall, 2005.
[17] Kelly WR, Murphy KE, Becker DA, Mann JL. Determination of Cr in certified reference material HISS-1, marine sediment, by cold plasma isotope dilution ICP-MS and INAA: comparison of microwave versus closed (carius) tube digestion. J Anal Atomic Spectrom 2003; 18: 166-9.

[18] Yang L, Lam JWH, Strugeon RE, McLaren JW. Determination of marine sediments for quantitative recovery of chromium and inductively coupled plasma mass spectrometric analysis. J Anal Atom Spectrom 2003; 13: 1245-8.

[19] Xue H, Sigg L, Gächter R. Transport of $\mathrm{Cu}, \mathrm{Zn}$ and $\mathrm{Cd}$ in a small agricultural catchment. Wat Res 2000; 34: 2558-68.

[20] Canadian Council of Ministers of the Environment [homepage on the Internet]. Available from: http://st-ts.ccme.ca/

[21] National Oceanic and Atmospheric Administration [homepage on the Internet]. Washington. Available from: http://response. restoration.noaa.gov/book shelf/121 sedi qual guide.pdf

[22] Choueri RB, Cesar A, Abessa DMS , et al. Development of sitespecific sediment quality guidelines for North and South Atlantic littoral zones: Comparison against national and international sediment quality benchmarks. J Hazard Mater 2009; 170: 320-31.

[23] Rodríguez-Barroso MR, Benhamou Y, El Moumni B, El Hatimi I, García-Morales, JL. Evaluation of metal contamination in sediments from north of Morocco: Geochemical and statistical approaches. Environ Monit Assess 2009; 159: 169-81

[24] Taylor SR. Abundance of chemical elements in the continental crust: a new table. Geoch Cosmoch Acta 1964; 28:1273-85.

[25] Sabhi Y, Chaoui M, El Quesear S, Bakkas S, Ramdani M Identification of the Northern Moroccan hot spots and contamination baseline of coastal sediments by heavy metals. Bulletin de l'Institut Scientifique 1999-2000; 22: 59-69.

[26] Tahri M, Benyaich F, Bounakhla M, et al. Multivariate analysis of heavy metals contents in soils, sediments and water in the region of Meknes (Central Morocco). Environ Monit Assess 2005; 102: 405 17.

(C) Benomar et al.; Licensee Bentham Open.

This is an open access article licensed under the terms of the Creative Commons Attribution Non-Commercial License (http://creativecommons.org/licenses/by$\mathrm{nc} / 3.0 /$ ), which permits unrestricted, non-commercial use, distribution and reproduction in any medium, provided the work is properly cited. 